\title{
Capítulo 1 \\ Procedimiento legislativo especial para la paz y separación de poderes: un debate constitucional ${ }^{1}$
}

JHEISON TORRES ÁvILA ${ }^{2}$ Andrés Abel RodrígueZ Villabona ${ }^{3}$

\section{Introducción}

$\mathrm{Z}^{1}$ concepto de control del poder es el que mejor define lo que - puede entenderse por constitucionalismo. Ahora bien, son muchos y de muy diversa índole los mecanismos que se han propuesto

1 El título del presente capítulo obedece al resultado del trabajo investigativo de la Maestría en Derecho Público de la Facultad de Derecho de la Universidad Santo Tomás desde el proyecto de investigación "Desafío del derecho público en el marco del posconflicto", gestionado con recursos de la Universidad Santo Tomás, en el marco del Grupo de Investigación en Derecho Público Francisco de Vitoria de la misma Facultad.

2 Profesor de la Universidad Santo Tomás y profesor asociado de la Universidad Nacional de Colombia.

3 Profesor de la Universidad Santo Tomás y profesor asociado de la Universidad Nacional de Colombia. 
y desarrollado para alcanzar este objetivo. Entre ellos, los de naturaleza jurídica e institucional desempeñan un papel relevante en el desarrollo del derecho constitucional, pero aquellos vinculados a lo que se conoce como la división o separación de poderes parecen ocupar un lugar central si se busca alcanzar el mencionado propósito. Teniendo esto presente, algunos han puesto en duda que se preserve este mecanismo de control del poder en el denominado "procedimiento legislativo especial para la paz” previsto en el artículo 1 del Acto Legislativo 01 de 2016, en la medida en que se le otorgan mayores competencias al ejecutivo en el inicio y el desarrollo del trámite legislativo y en la determinación de los contenidos de los proyectos que se ponen a consideración del legislativo. Esta crítica se plantea no solo frente al principio de separación de poderes en general, sino además frente a la estructura que la Constitución de 1991 estableció para su desarrollo en nuestro país.

Para examinar el alcance de este tipo de reparos es necesario proceder a una revisión de las tensiones que se producen en el desarrollo de los mecanismos particulares para la consecución de la paz y, en especial, en el procedimiento legislativo especial para la paz. Para ello se comenzará con una breve presentación sobre la trascendencia de la división de poderes para el constitucionalismo, de manera que sea posible analizar, en un segundo momento, el modelo que para realizar dicho principio se adoptó en la Constitución de 1991. Bajo estos parámetros se abordará, en tercer lugar, la noción de justicia transicional en el constitucionalismo y, finalmente, se analizará el caso de los procedimientos abreviados legislativos y sus tensiones con la separación de poderes y los derechos fundamentales.

\section{Constitucionalismo y separación de poderes}

El nombre de Charles Louis de Secondat, barón de Montesquieu (16891755), está profundamente ligado a la doctrina de la separación de poderes, al punto que se le considera uno de sus principales precursores. En el marco de la crítica permanente que él hace del despotismo como 
antítesis de la libertad política (Fetscher, 2002, p. 109; Larrère, 2003, p. 470), aborda dicha doctrina en su más célebre obra, Del espíritu de las leyes (1748). En el libro XI, que se ocupa "De las leyes que forman la libertad política en su relación con la constitución”, hace en el capítulo vi un homenaje a la constitución de Inglaterra, porque es aquella que tiene "como objeto directo la libertad política" (Montesquieu, 1984, t. I, p. 143). Esto ha sido posible gracias a la organización peculiar que en este país tienen los poderes públicos:

Hay en cada Estado tres clases de poderes: el poder legislativo, el poder ejecutivo de los asuntos que dependen del derecho de gentes y el poder ejecutivo de los que dependen del derecho civil. Por el poder legislativo, el príncipe, o el magistrado, promulga leyes para cierto tiempo o para siempre, y enmienda o deroga las existentes. Por el segundo poder, dispone de la guerra y de la paz, envía o recibe embajadores, establece la seguridad, previene las invasiones. Por el tercero, castiga los delitos o juzga las diferencias entre particulares. Llamaremos a éste poder judicial, y al otro, simplemente, poder ejecutivo del Estado. [...] Todo estaría perdido si el mismo hombre, el mismo cuerpo de personas principales, de los nobles o del pueblo, ejerciera los tres poderes. (Montesquieu, 1984, t. I, pp. 143-144)

Para Montesquieu, con esta estructura institucional se garantiza el mejor modelo en la conformación del Gobierno, el de carácter mixto y moderado, el que permite que "no se pueda abusar del poder", porque, "por la disposición de las cosas, el poder frena al poder" (Montesquieu, 1984, t. I, p. 142). No se necesitó de mucho para que estas consideraciones, casi desde el momento en que se dieron a conocer, fueran asumidas como la exposición más acabada del principio de separación de poderes. Ahora bien, hay que tener presente que este principio, en el marco de

la teoría de la constitución inglesa, ocupa el centro de la sociología política de Montesquieu, no porque represente un modelo válido para todos los países, sino porque, en el mecanismo constitucional de una monarquía, permite recuperar los fundamentos de un estado moderado y libre. (Aron, 2004, p. 39) 
Es por esta razón que en Del espíritu de las leyes "no se encuentra ni una separación funcional ni una separación material de las autoridades estatales" (Eisenmann, 1933, p. 166), dado que no insistía en una división tajante entre el legislativo, el ejecutivo y el judicial, sino más bien en la distribución de la función legislativa entre el rey y las dos cámaras del parlamento inglés, la Cámara de los Comunes y la Cámara de los Lores. Se trata entonces de la defensa de un gobierno equilibrado en el que los distintos órganos realizan un balance constitucional capaz de obstaculizar la afirmación de un poder absoluto. De todas maneras, "con su insistencia en el acoplamiento de los poderes y su mutua delimitación se adelantó al moderno Estado constitucional liberal" (Fetscher, 2002, p. 131) y tuvo una enorme influencia en la elaboración de las constituciones de finales del siglo xviII y comienzos del xix en América y en Europa.

Esta característica distintiva de la doctrina de Montesquieu se explica por el hecho de que con ella se puede hacer referencia a cuatro conceptos: el de constitución mixta, el de constitución equilibrada, el de separación de poderes y el de frenos y contrapesos (checks and balances). Todos ellos son variaciones del constitucionalismo, pero han sido construidos teniendo presentes diferentes elementos, funciones y propósitos del Gobierno y la sociedad. En cuanto que han sido formulados en diversas épocas y sobre bases discrepantes, estos cuatro conceptos, en cierta medida, se solapan y pueden contradecirse ${ }^{4}$. La originalidad de Montesquieu consiste en su peculiar manera de unirlos y combinarlos en vez de haber inventado uno de ellos, pues ya figuraban en la discusión constitucional en Inglaterra desde tiempo atrás (Richter, 1990, p. 39).

En efecto, en este país la implantación del sistema parlamentario con gobierno de gabinete — que se inició en la primera mitad del

4 Es por esto que Karl Löewenstein (1983) asegura que "lo que corrientemente, aunque erróneamente, se suele designar como la separación de los poderes estatales, es en realidad la distribución de determinadas funciones estatales a diferentes órganos del Estado. El concepto de 'poderes', pese a lo profundamente enraizado que está, debe ser entendido en este contexto de una manera meramente figurativa” (p. 55). 
siglo XVIII- a través del proceder de los partidos, los ministros y los monarcas permite ver cómo se fueron construyendo las relaciones entre el ejecutivo y el parlamento y cómo se fue configurando en la práctica el principio de la separación de poderes. El liderazgo político inglés era consciente de la necesidad de asegurar relaciones armoniosas entre los diversos componentes de la estructura político-institucional, especialmente entre el rey y el parlamento, si se pretendía que la maquinaría del gobierno trabajara razonablemente bien. Fue así como se mantuvo la prerrogativa del rey de disolver el parlamento en cualquier momento — competencia que al pasar los años dependerá de la iniciativa del primer ministro- mientras que, por su parte, el parlamento podía contraponerse al ejecutivo negando soporte financiero, desmantelando el ejército o, en últimas, retirando la confianza (mediante el voto de censura) al Gobierno o a algunos de sus ministros. Estos mecanismos de recíproco influjo impedían así el bloqueo entre los dos poderes, que, sin otra válvula de escape, impondría el recurso a vías extralegales. Con todo, el bloqueo no solo se evitaba con estas fórmulas institucionales, sino también usando la sugestión que sobre los miembros del parlamento causaban los favores, los honores, las pensiones, los cargos y los demás beneficios que podían otorgar los nada desdeñables poderes gubernamentales del ejecutivo (Duverger, 1976, p. 18; Hermet, 1996, p. 31). En el origen del sistema parlamentario no solo están los aportes de la evolución constitucional inglesa desde el punto de vista institucional, sino también una serie de prácticas que en ocasiones no deja muy bien parado el goodwill de los políticos ingleses de los siglos XVIII y xIX.

Ahora bien, fue en los Estados Unidos en donde la separación de poderes propuesta por Montesquieu tuvo una influencia notable, en especial durante el debate que se dio en torno a la ratificación, por cada uno de los Estados, de la constitución que había aprobado la convención de Filadelfia en septiembre de 1787. Entre los numerosos documentos que se publicaron a favor y en contra de la ratificación, hubo una serie de artículos de prensa escritos por Alexander Hamilton (1757-1804), James Madison (1751-1836) y John Jay (1745-1829) que posteriormente se compilaron en un solo volumen bajo el título de $E l$ federalista. Esta ha sido considerada "una obra clásica de la literatura 


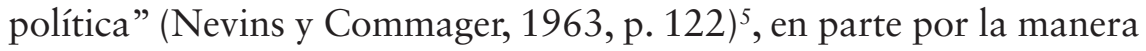
como aborda la cuestión de la separación de poderes. Para sus autores no consiste solamente en radicar distintas funciones en cada órgano (ejecutivo, legislativo y judicial), sino en establecer también un sistema de frenos y contrapesos (checks and balances) en donde cada poder controla las eventuales extralimitaciones del otro ${ }^{6}$. De esta forma, existe una marcada independencia entre los poderes, dado que cada uno se mantiene en funciones durante todo el periodo prefijado de sus mandatos y es imposible que el uno afecte la composición política del otro (como sí sucede en el parlamentarismo británico a través de los mecanismos de disolución del parlamento y voto de censura a los ministros), sin que ello signifique que no fueran previstos dispositivos para contrarrestar las posibles intromisiones de un poder en el otro. De esta manera, como los distintos poderes se controlan, se tiene un gobierno, por esencia, limitado y respetuoso de los derechos de las minorías y de las personas.

Este mecanismo de separación estricta de poderes es una de las grandes invenciones del constitucionalismo estadounidense, conocida con el nombre de régimen presidencial, por oposición al régimen parlamentario, que es un sistema de separación flexible de poderes en cuanto que hay una influencia orgánica del legislativo en la conformación del ejecutivo y viceversa. De manera contraria, en el régimen presidencial hay una separación orgánica estricta, pero también una interdependencia funcional que permite que los distintos poderes se

5 "Se ha considerado que sus argumentaciones [las de El federalista], acerca de la Constitución propuesta, tuvieron gran influencia en su tiempo, siendo ampliamente aceptadas como fuentes autorizadas de interpretación constitucional" (Pritchett, 1965, p. 45). Para una recopilación en español de algunos artículos de El federalista y de algunos escritos de los antifederalistas, véase Sánchez-Cuenca y Lledó (2002).

6 "La mayor seguridad contra la concentración gradual de los diversos poderes en un solo departamento [en el ejecutivo, el legislativo o el judicial] reside en dotar a los que administran cada departamento de los medios constitucionales y los móviles personales necesarios para resistir las invasiones de los demás” (Hamilton, Madison y Jay, 2001, p. 220). 
controlen unos a otros ${ }^{7}$. Por ejemplo, en el régimen presidencial estadounidense el ejecutivo controla los desafueros del legislativo a través del reconocimiento de un veto a favor del presidente ${ }^{8}$. Ahora bien, según los autores de El federalista, el legislador no requiere una protección especial, pues "en el gobierno republicano predomina necesariamente la autoridad legislativa” (Hamilton, Madison y Jay, 2001, p. 221). Los que precisarían de dispositivos particulares de protección son el ejecutivo - sobre todo frente a las usurpaciones del legislativo-y el judicial, para que este último, garantizada su independencia, desempeñe un papel fundamental en la consolidación de este tipo de democracia.

En esta misma línea, durante la Revolución francesa este principio quedará íntimamente vinculado al concepto mismo de constitución, de manera que "pasa a asociarse a la idea de libertad política y de división de poderes” (Beaud, 2009, pp. 10-11). De hecho, los líderes revolucionarios no utilizaron el término constitución para designar cualquier forma de gobierno, sino para identificar aquella que, sometida a límites jurídicos, garantizaba los derechos de los ciudadanos y se basaba en la separación de poderes. Entre los numerosos escritos de la época a este respecto se destacan los de Emmanuel Sieyès (1748-1836), quien en un discurso de 1789, titulado Preliminar de la constitución, afirmó que "el verdadero sentido de la palabra Constitución [...] abarca la formación y la organización interiores de los diferentes poderes públicos [...], es relativa al conjunto y a la separación de los poderes públicos", los cuales "están todos sujetos a leyes, reglas y formas que no pueden cambiar a su antojo", porque "tal y como no pudieron constituirse a sí mismos, tampoco pueden cambiar su Constitución” (Sieyès, 1993,

7 Es clásica la diferenciación propuesta por Hauriou cuando señala que el equilibrio en los regímenes políticos basados en la separación de poderes "ha sido buscado, en consecuencia, de dos maneras: en primer lugar, por medio de una separación tajante o acentuada entre los poderes, que conduce, con su aislamiento, al régimen presidencial; en segundo lugar, por medio de una separación matizada o atenuada que facilita su colaboración, y da como resultado el régimen parlamentario, llamado también —según una expresión más juiciosael Gobierno de Gabinete" (Hauriou, Gicquel y Gélard, 1980, p. 267).

8 El veto presidencial de carácter suspensivo es previsto por el parágrafo segundo, sección séptima del artículo 1 de la Constitución. 
p. 183). Ahora bien, su concepción de la separación de los poderes se aparta en varios aspectos de la concepción liberal clásica. En efecto, según Montesquieu y la tradición inglesa, la separación de los poderes entraña no solo cierta igualdad entre ellos, sino tá mbíén la posibilidad de controles recíprocos. Para Sièyes, en cambio, como para la mayoría de sus contemporáneos franceses, la división de los poderes era más un principio de no interferencia y de protección del legislativo que un principio destinado al control recíproco. De todas formas, sus tesis tuvieron un papel destacable entre los presupuestos del debate que se dio en la Asamblea Nacional sobre si Francia tenía o no una constitución. Se impuso la tendencia que daba una respuesta negativa a esta cuestión, razón por la cual el artículo 16 de la Declaración de los Derechos del Hombre y del Ciudadano de 1789 dispuso que "toda sociedad en la que no esté asegurada la garantía de los derechos ni determinada la separación de los poderes, no tiene constitución".

Esta disposición es el fundamento más conocido para el surgimiento de un concepto material de constitución en sentido estricto o un "concepto mínimo" de constitución (Tomás y Valiente, 1996, p. 49), que se diferencia de un concepto material de constitución en sentido amplio: para este último, la constitución es un conjunto de normas que cumple con algunas condiciones formales o que regula la organización de los órganos del Estado y el proceso de creación del derecho positivo; para el primero, por su parte, es necesario además que la constitución tenga unos contenidos determinados que respondan a ciertas exigencias políticas y éticas, que al final del siglo Xvin eran la limitación del poder político mediante la garantía de los derechos individuales (según la concepción del iusnaturalismo racionalista) y la separación o distribución de los poderes (Grimm, 2006, p. 60; Matteucci, 2005, p. 346). Por consiguiente, para esta concepción no todas las sociedades tienen necesariamente una constitución, sino únicamente aquellas que poseen una que corresponda a determinados criterios materiales, entre ellos, justamente, la separación de poderes ${ }^{9}$.

9 Teniendo esto en cuenta, es posible diferenciar, como lo hace Josep Aguiló, entre constitución necesaria y constitución contingente, "lo que supone oponer aquellos conceptos de Constitución que presuponen que todo sistema 
De hecho, no son pocos los autores que han tratado de encontrar los contenidos sustantivos que definen la constitución destacando este principio. Entre los intentos que se han hecho cabe destacar el de Karl Löewenstein (1983), quien define la constitución como "el dispositivo fundamental para el control del proceso del poder" (p. 149), que se concreta en cinco elementos fundamentales, entre los cuales la separación de poderes ocupa un lugar central. Estos elementos son: 1) la asignación de diversas funciones o competencias a diferentes órganos estatales, con lo cual se evita la concentración del poder en una sola instancia y se realiza el principio de separación de poderes; 2) al lado de la separación y la distribución, el establecimiento de mecanismos de cooperación y equilibrio entre las instituciones, como el de los frenos y contrapesos; 3) el reconocimiento del electorado, conformado por todos los adultos mayores de edad, como el árbitro supremo en los conflictos entre los órganos del poder público para evitar así que uno de ellos se imponga autocráticamente sobre los demás, lo cual es expresión del carácter demoliberal del constitucionalismo contemporáneo; 4) la previsión de mecanismos de reforma o revisión de la constitución, con el propósito de adaptarla a las cambiantes condiciones sociales y políticas e impedir el recurso a medios extraconstitucionales, revolucionarios, ilegales o violentos para lograr este cometido; 5) la afirmación explícita de los derechos y las libertades fundamentales de las personas y su protección frente a la acción de los detentadores del poder (Löewenstein, 1983, p. 153).

La oposición entre un concepto amplio y un concepto estricto de constitución tiene consecuencias directas en la manera como se puede concebir el constitucionalismo. Para Carlos Nino (1992), esta diferencia implica que hay dos sentidos de constitucionalismo: por una parte, un sentido "mínimo" que "se refiere al requerimiento de que un Estado tenga una constitución en el vértice de su sistema jurídico", entendida como "conjunto de normas que dispone la organización básica del poder político y la relación entre el Estado y los individuos”; por otra parte, un sentido "pleno" de constitucionalismo que "requiere no solo

jurídico-político estable cuenta con una Constitución a aquellos otros conceptos que no lo presuponen” (Aguiló, 2004, p. 25). 
la existencia de normas que organizan el poder y que están, en cierto modo, atrincheradas frente al proceso legislativo normal, sino también, y preeminentemente, que se satisfagan ciertas exigencias acerca del procedimiento y contenido de las leyes que regulan la vida pública" (pp. 3-4). Entre estas exigencias se encuentra el establecimiento de alguna forma de división o separación de poderes, postura que tiene su fundamento histórico en el artículo 16 de la declaración de derechos de 1789 que ya se ha citado antes. En este sentido, se afirma que el constitucionalismo "al dividir el Poder, ofrece un sistema de limitaciones efectivas a la acción gubernamental" a través de "métodos y técnicas en virtud de las cuales se mantienen y establecen tales limitaciones" (Friedrich, 1975, t. I, p. 68).

No obstante, la separación de poderes, en particular en las democracias contemporáneas, no parece ser suficiente para impedir el arbitrio de una mayoría que llegue a dominar las instituciones estatales. Como lo explica Nicola Matteucci (2005),

la actual división de órganos puede obstaculizar o disminuir la voluntad de un partido fuerte o de una mayoría estable, pero es totalmente insuficiente para garantizar tanto los derechos de las minorías como impedir el abuso del poder respecto de los ciudadanos, en la medida en que estos órganos pueden estar en manos del mismo partido. (p. 342)

Por consiguiente, la separación de poderes es más bien uno de los mecanismos institucionales para lograr el principal propósito que se ha trazado el constitucionalismo en su larga historia, es decir, la "limitación jurídica del gobierno. [...] El rasgo característico más antiguo, constante y duradero del verdadero constitucionalismo continúa siendo, como lo ha sido casi desde el comienzo, la limitación del gobierno por el derecho" (Mcllwain, 1991, p. 37).

\section{La división de poderes en el constitucionalismo de 1991}

Siguiendo el modelo de evolución del Estado de derecho al Estado social de derecho, la Constitución colombiana de 1991 preservó el 
principio de la división de poderes. Esto es apenas lógico porque dicho tránsito no implica la eliminación de muchos de los pilares del Estado liberal, sino más bien su reinterpretación y complementariedad al compás del concepto de igualdad material. De esta manera, destaca la Corte Constitucional sobre el particular:

La separación de poderes es también un mecanismo esencial para evitar la arbitrariedad, mantener el ejercicio de la autoridad dentro de los límites permitidos por la Carta y asegurar así la libertad y seguridad de los asociados. La lógica de este dispositivo, no por conocida deja de ser esencial: la división de la función pública entre diferentes ramas permite que el poder no descanse únicamente en las manos de una sola persona o entidad, a fin de que los diversos órganos puedan controlarse recíprocamente. Esto significa que, como esta Corporación lo había señalado, la consagración de diversas ramas del poder y de órganos autónomos se lleva a cabo "con el propósito no solo de buscar mayor eficiencia en el logro de los fines que le son propios, sino también, para que esas competencias así determinadas, en sus límites, se constituyeran en controles automáticos de las distintas ramas entre sí, y, para, según la afirmación clásica, defender la libertad del individuo y de la persona humana." Por ello, como lo ha recordado esta Corte, "la separación de las ramas del poder público es inherente al régimen democrático y constituye uno de sus elementos procedimentales de legitimación”. (Sentencia C-251 de 2002, M. P. Eduardo Montealegre)

Ahora bien, la determinación de dicho principio recibió algunos cambios en el nuevo marco constitucional. En primer lugar, su disposición formal implica transformaciones respecto a la tradición desarrollada, en especial en los últimos cincuenta años, pues supone una estructura que va más allá de la visión tripartita del poder para plantear un esquema más amplio que se desarrolla de acuerdo con las necesidades planteadas por el constituyente. Señala el artículo 113 de la Constitución:

Son ramas del Poder Público, la legislativa, la ejecutiva y la judicial. Además de los órganos que las integran existen otros, autónomos 
e independientes, para el cumplimiento de las demás funciones del Estado. Los diferentes órganos del Estado tienen funciones separadas, pero colaboran armónicamente para la realización de sus fines.

Como se observa, además de las ramas clásicas del poder público, se establece una estructura fundada en los denominados órganos autónomos. Esto es posible debido a la aplicación del principio de soberanía popular que establece en el pueblo el poder del Estado, lo cual genera por contera que las denominadas ramas u órganos sean mandatarios de este poder popular. Todo ello implica que el legislador, por ejemplo, no tenga un poder en sí mismo, sino una competencia, delegada y delimitada por el poder constituyente, con las instituciones y los procedimientos predefinidos.

Por lo demás, el reconocimiento de los órganos autónomos es la aceptación de una versión actualizada de la estructura del Estado, en donde la especialización de competencias hace recrear una propuesta en donde el poder soberano se enfoca en su instrumentalización constitucional y no en el ejercicio directo de la soberanía ${ }^{10}$. La banca central, los órganos electorales y los órganos de control se destacan justamente en esta mirada de especialización, pero, a la vez, de comprensión de que estas funciones no pueden estar concentradas o ser dependientes de las ramas tradicionales. Como lo destaca la Corte Constitucional:

Además de las tradicionales ramas legislativa, ejecutiva y judicial, la Constitución establece órganos, distintos de los que integran aquéllas, que tienen por característica la de ser autónomos e independientes, "para el cumplimiento de las demás funciones del Estado" [...]. El Banco de la República, el Consejo Nacional Electoral y la

10 El esquema planteado por la Constitución de 1991 que recoge lo dispuesto por la reforma de 1968 al intentar dotar al Estado de herramientas para construir un orden intervencionista es de vital importancia para interpretar qué labores debe realizar el Estado, así como para la construcción de vías alternativas para lograr la efectividad de sus funciones. La diferencia es que ahora el ejecutivo, que en aquella reforma centralizaba todo el poder, se ve controlado eficazmente por otros poderes. Adicionalmente, sus funciones se establecen dentro de un claro marco conceptual, impuesto por el Estado social. 
Registraduría Nacional del Estado Civil, la Procuraduría General de la Nación, la Contraloría General de la República y la Comisión Nacional de Televisión son órganos independientes de la indicada categoría. (Sentencia C-350 de 1997, M. P. Fabio Morón)

Esto significa que tales órganos no hacen parte de ninguna de las ramas tradicionales del poder público, ni cumplen sus funciones, ni pueden ser dirigidos por ellas, lo cual no obsta para opere la coordinación en el ejercicio de sus actividades. Esto es así porque, como afirma Löewenstein (1983):

Lo que en realidad significa la así llamada "separación de poderes", no es, ni más ni menos, que el reconocimiento de que por una parte el Estado tiene que cumplir determinadas funciones -el problema técnico de la división del trabajo- y por otra, los destinatarios del poder salen beneficiados si estas funciones son realizadas por diferentes órganos: la libertad es el thelos ideológico de la teoría de la separación de poderes. La separación de poderes no es sino la forma clásica de expresar la necesidad de distribuir y controlar respectivamente el ejercicio del poder político. (p. 55)

De esta forma, las otras instituciones no tienen que pertenecer obligadamente a alguna de las divisiones clásicas, sino acatar el modelo de respeto a los derechos y del control político y jurídico y subordinarse al querer del constituyente a través de la Constitución.

Dentro de las características de estos poderes, se preserva la fórmula del control fundada en su vinculación a la ley y, desde luego, al respeto de todos los derechos inscritos en la Constitución. A la par del ejercicio del control, les adjudica autonomía e independencia expresadas en términos políticos, jurídicos y presupuestales, siempre bajo la égida de la colaboración entre los mismos.

En segundo lugar, se establece la colaboración armónica, compatible con los objetivos constitucionales establecidos en los artículos 1 y 2 de la Constitución, así como con una interpretación desde la materialidad constitucional. Esta interpretación del orden constitucional establece entonces que la realización de los valores y principios constitucionales debe estar por encima de elementos ajenos a estos. De ahí 
que dicha colaboración tenga al menos las siguientes consecuencias: por un lado, un régimen completo de responsabilidades de todos los que integran el Estado, y, por el otro, una sujeción al poder popular expresado en el texto constitucional. Ahora bien, esta colaboración no supone que se produzcan dos consecuencias nocivas: la carencia de responsabilidades y la confusión de funciones. Las dos situaciones resultan indeseables, y riñen, desde luego, con el thelos constitucional. Señala la Corte:

El principio este de colaboración armónica no puede llegar al extremo de desconocer el reparto funcional de competencias, ni el ampliamente explicado principio de división de poderes. Y por lo mismo, es errado afirmar que el principio de la colaboración armónica permite fusionar tareas y compartir responsabilidades sobre aspectos claramente diferenciados en el ordenamiento constitucional. Además, el principio de colaboración armónica no puede ser transformado por el Legislador en un deber de colaboración exigible cuando lo disponga el ejecutivo. (Sentencia C-251 de 2002, M. P. Clara Inés Vargas)

Sin duda alguna, esta complejidad que muestra la parte orgánica coincide con las funciones que asume el Estado social (García Pelayo, 2005), pues el esquema demoliberal resulta insuficiente para proteger y promover el conjunto complejo de intereses de las sociedades actuales. Esta complejidad no se traduce únicamente en el número de poderes que encarna el Estado. Las relaciones entre los poderes y la sociedad también conforman un entramado que debe ceñirse a las antiguas reglas del control jurídico, pero que necesitan ampliación y una mayor efectividad ante el peligro de excesos. Al respecto, señala Haberle (2002) que "gracias a la democracia aparece el carácter de autonomía del ámbito público estructurado pluralmente como garantía institucionalizada, siendo, por tanto, el ámbito de preconfiguración de la voluntad política, de las cadenas legitimatorias entre el pueblo y los órganos del Estado" (p. 149).

Es aquí donde el control, tanto desde el punto de vista jurídico como del político, cumple una de sus labores fundamentales. Este control no se limita a la vista formal-funcional de las actuaciones de 
dichos poderes, sino que trasciende en un verdadero control material de sus actuaciones. La materialidad del control es la garantía que impone el nuevo enfoque, ya que esta sustancialidad debe ser respetada por todos y cada uno de los órganos del Estado, no como meros mandatos sin efectos, sino como verdaderas obligaciones que pueden ser determinadas en acciones y restricciones concretas. Esta materialidad intenta desarticular la inercia burocrática que en muchas ocasiones viola los derechos fundamentales, al primar la nota mecánica de sus actuaciones sobre los fines esenciales que impone la Constitución desde su artículo 1 y que define de manera explícita el artículo 2:

Son fines esenciales del Estado: servir a la comunidad, promover la prosperidad general y garantizar la efectividad de los principios, derechos y deberes consagrados en la Constitución; facilitar la participación de todos en las decisiones que los afectan y en la vida económica, política, administrativa y cultural de la Nación; defender la independencia nacional, mantener la integridad territorial y asegurar la convivencia pacífica y la vigencia de un orden justo. Las autoridades de la República están instituidas para proteger a todas las personas residentes en Colombia, en su vida, honra, bienes, creencias, y demás derechos y libertades, y para asegurar el cumplimiento de los deberes sociales del Estado y de los particulares.

En este manual de funciones del artículo 2 se resumen los parámetros de actuación del poder público, que se pueden sintetizar en la búsqueda de la estabilidad y el aseguramiento de unidad nacional, todo a la luz de la fórmula del Estado social de derecho y los valores y derechos que contiene. Las limitaciones a los poderes públicos tendrán entonces una estructura dual, es decir, desde un punto de vista formal con el conjunto de mecanismos concretos de control, como el control de constitucionalidad, la moción de censura y la sanción de las leyes por parte del ejecutivo, entre otros, y desde un punto de vista material al someterse la interpretación de los actos del poder constituido y los órganos autónomos al cumplimiento de los fines constitucionales. El constitucionalismo material aparece aquí como uno de los grandes pilares de la comprensión de toda la Constitución al instituirse como una 
metodología que defiende el cumplimiento transcendente de los valores y los principios determinados en la fórmula política y que acentúan la búsqueda de la eficacia constitucional. Este elemento será determinante para la comprensión del modelo jurídico de la justicia transicional, pues la materialidad de estos principios define los contornos competenciales de las ramas y los órganos del Estado y establecen una finalidad: el cumplimiento y el respeto constitucional como máxima del Estado social de derecho. Sobre los límites materiales con respecto al legislador, se ha referido la jurisprudencia constitucional:

El legislador encuentra límites materiales al ejercicio de su función, representados por valores, principios y mandatos constitucionales, fuera de los cuales no le es posible obrar, por plausible y encomiable que sea el objetivo buscado con las normas que profiere. Puede tratarse inclusive de una disposición mediante la cual se busque dar desarrollo o realización a un precepto de la Carta: si se opone a otro u otros, o al sistema fundamental en su conjunto, será función del juez de constitucionalidad retirarla del ordenamiento jurídico. (Sentencia C-257 de 1997, M. P. José Gregorio Hernández)

Lo establecido aquí por la Corte Constitucional envuelve la actividad de cualquier órgano, lo que pone a todos los poderes en un nivel igualitario frente a los mandatos de la Constitución, incluyendo al órgano legislativo, cuya legitimidad democrática tiene una barrera infranqueable: la que lo somete a la "fórmula Política" (Canosa, 1988).

En el esquema propuesto por la Constitución, el poder público tiene como función primordial el respeto y la realización de la Ley Fundamental, y, en este sentido, los derechos sociales comprometen cada una de las actividades autorizadas por la Constitución, tanto las del legislador como las del juez constitucional. Se expresa Pérez Royo (1988) sobre el tema:

Una vez que existe un Estado constitucional digno de tal nombre, el problema de los límites del poder político acaba siendo siempre un problema de interpretación de la Constitución. Se comprende perfectamente el porqué de la insistencia en los 
límites de la Justicia Constitucional. Puesto que en todo Estado se tiene que poner fin en algún momento a un control de tipo externo, si no hay un sistema de control de constitucionalidad de la ley, es el órgano legislativo el que tiene que autolimitarse al interpretar el texto constitucional, para no transformar la prerrogativa de la interpretación de la Constitución en un monopolio de hecho e interferir indebidamente en la competencia de otros órganos del Estado. (pp. 22-23)

El desarrollo de una práctica de colaboración entre las ramas del poder público es un elemento indispensable para el desarrollo de los derechos. Sin este tipo de cooperación más allá del mero equilibrio, los derechos están destinados a una defensa fragmentada por parte de algunas voces dentro del Estado. Por ello, es un aspecto de enorme relevancia, dentro de la teoría del poder de la Constitución de 1991, el intento de morigerar las diferencias entre las parcelas de poder en el interior del Estado para que se integren en un verdadero proyecto común. De ahí que el control político de unos no baste para fomentar el desarrollo de toda la Constitución, sino que se requiere de un eje material vertebrador de las acciones del poder del Estado.

Para el caso del proceso de paz, visto en su conjunto, no solo el ejecutivo se encuentra comprometido con esta empresa, sino que, además, todas las ramas y órganos deben impulsar dicha iniciativa. Le corresponde al Gobierno liderar este campo, pero está claro que en un Estado constitucional no puede una sola rama realizar esta tarea y debe establecerse la posibilidad real de construir el entramado que implica la aplicación de los Acuerdos de Paz.

En el caso concreto de los Acuerdos de Paz, se hace imperioso determinar qué significado tiene la justicia transicional como concepto vertebrador para la superación del conflicto armado y reconocer su excepcionalidad, con el objeto de reconstruir una institucionalidad que nunca podrá estar completa mientras existan las masivas y sistemáticas violaciones a los derechos que deja la guerra. Por ello, a continuación revisaremos este tema para luego abordar una mirada en perspectiva constitucional de los procedimientos abreviados legislativos del Acto Legislativo 01 de 2016. 


\section{La justicia transicional y el constitucionalismo}

La justicia, como elemento central del Estado de derecho, establece los mecanismos por medio de los cuales las personas pueden proteger sus derechos. Esta misma justicia se encarga también de castigar a quienes han vulnerado los bienes jurídicamente tutelados. Con todo, cuando en una sociedad se violan de forma sistemática los derechos y los responsables no obtienen castigos, dicha sociedad se encuentra inmersa en un escenario de inestabilidad y de carencias sistemáticas de las más importantes garantías que pregonan los Estados constitucionales. De allí que cuando un régimen político ha consentido, organizado, generado, instigado o incluso cuando debido a su imposibilidad de control real ha permitido que se presenten violaciones sistemáticas a los derechos de las poblaciones se hace indispensable la búsqueda de mecanismos que permitan la estabilización política.

Por otra parte, la generación de condiciones que permitan superar la violencia y que establezcan los medios para la garantía de la dignidad de las personas y sus comunidades crea inmensas presiones sobre la estructura constitucional existente al momento de desencadenarse y desarrollarse el conflicto. Esta es, de hecho, la gran paradoja transicional. Por ello, la justicia transicional puede ser interpretada como "la variedad de procesos y mecanismos asociados con los intentos de una sociedad por resolver los problemas derivados de un pasado de abusos a gran escala, a fin de que los responsables rindan cuentas de sus actos, servir a la justicia y lograr la reconciliación” (Organización de las Naciones Unidas, 2005). Por consiguiente, "la justicia transicional es el conjunto de medidas judiciales y políticas que diversos países han utilizado como reparación por las violaciones masivas de derechos humanos. Entre ellas figuran las acciones penales, las comisiones de la verdad, los programas de reparación y diversas reformas institucionales" (International Center for Transitional Justice, 2010).

De esta forma, la justicia transicional es el proceso, con sus herramientas, que permite la estabilización de un régimen político cuyas condiciones se establecen sobre la base de los derechos y sus garantías, 
después de un periodo de violaciones sistemáticas a esas mismas garantías. Estas medidas se articulan sobre tres principios fundamentales: verdad, justicia y reparación, que se convierten en los derroteros interpretativos de su aplicación (Gutiérrez, 2014). Ahora bien, ¿esta forma de justicia es otra justicia diferente a la que se pregona en los Estados liberales, y mucho más en los Estados constitucionales? En nuestra opinión, sí tiene elementos diversos dado que posee una fundamentación diferenciada y fines que, aunque cercanos a la justicia tradicional, no son los mismos y por ello terminan planteando retos particulares a la justicia ordinaria (Castellanos, 2006). De todas maneras la cuestión es materia de debates, pues estos conceptos son difusos. Incluso la misma justicia transicional presenta diversas etapas históricas que tendrían acentos y formas diferenciadas que cambiarían la manera en que la entendemos y aplicamos y, en general, el proceso institucional en la que ella se soporta. Sobre este punto, señala Teitel (2003):

Los orígenes de la justicia transicional moderna se remontan a la Primera Guerra Mundial, sin embargo, la justicia transicional comienza a ser entendida como extraordinaria e internacional en el periodo de la posguerra después de 1945. La Guerra Fría da término al internacionalismo de esta primera fase, o fase de la posguerra, de la justicia transicional. La segunda fase o fase de la posguerra fría, se asocia con la ola de transiciones hacia la democracia y modernización que comenzó en 1989. Hacia finales del siglo xx, la política mundial se caracterizó por una aceleración en la resolución de conflictos y un persistente discurso por la justicia en el mundo del derecho y en la sociedad. La tercera fase, o estado estable, de la justicia transicional, está asociada con las condiciones contemporáneas de conflicto persistente que echan las bases para establecer como normal un derecho de la violencia. (p. 69)

Ahora bien, conforme al objeto del presente capítulo, nuestro esfuerzo no se encuentra en enfatizar los problemas conceptuales de la justicia transicional, así como su desarrollo teórico e histórico in extenso. Nuestro objetivo es únicamente observar las relaciones de este proceso con otros dos elementos: por un lado, el referido al concepto de control del poder, en particular mediante la separación de poderes, frente 
al constitucionalismo y la Constitución de 1991 y, por el otro, sus manifestaciones dentro del proceso transicional que se está desarrollando en la actualidad. Por ello, el objetivo de la justicia transicional es central para revisar estos cruces conceptuales. Al respecto, señala Migai Akech (2010) que

la justicia transicional no solo se refiere a la retribución por los errores del pasado o la prestación de la justicia a aquellos que han sufrido bajo regímenes represivos, sino que también trata de curar a la sociedad, facilitar la salida del autoritarismo, y establecer una sociedad justa basada en el imperio de la ley. (p. 10)

Así las cosas, la justicia transicional no es solo para establecer responsables de violaciones y obtener reparaciones, sino que el núcleo de su interés, adicionalmente, es el de permitir un cambio de régimen político o dirigirse a otro más garantista, que supere la violencia y brinde estabilidad y legitimidad al sistema constitucional resultante. La democracia y el imperio de la ley, o mejor, de la Constitución, serían los pilares de esta construcción política deseable. Pero este deseo de construir cambios políticos no es un esfuerzo sencillo, no solo porque las condiciones de negociación generalmente deben sortear numerosos obstáculos locales, sino también porque en la actualidad existen factores establecidos en el derecho internacional, tanto penal como de los derechos humanos, que hacen exigencias a quienes están negociando, en términos de reparación, verdad y justicia. Al respecto, señalan Uprimny y Saffon (2005) que estamos ante

aquellos procesos transicionales mediante los cuales se llevan a cabo transformaciones radicales de un orden social y político determinado; que enfrentan la necesidad de equilibrar las exigencias contrapuestas de paz y justicia. De hecho, por un lado, los procesos de Justicia Transicional se caracterizan por implicar en la mayoría de los casos —en especial cuando se trata de transiciones de la guerra a la paz- negociaciones políticas entre los diferentes actores, tendientes a lograr acuerdos lo suficientemente satisfactorios para todas las partes como para que éstas decidan aceptar la transición. Pero, por otro lado, los procesos de Justicia 
Transicional se ven regidos por las exigencias jurídicas de justicia impuestas desde el plano internacional, que se concretan en el imperativo de individualizar y castigar a los responsables de crímenes de guerra y de lesa humanidad cometidos en la etapa previa a la transición. De esta manera, mientras que las exigencias jurídicas antes mencionadas buscan proteger cabalmente los derechos de las víctimas de tales crímenes a la verdad, la justicia y la reparación, las necesidades de paz y reconciliación nacional propias de los procesos transicionales presionan en dirección opuesta, pues para que los responsables de crímenes atroces decidan aceptar dejar las armas y llegar a un acuerdo de paz, resulta necesario que encuentren incentivos atractivos para hacerlo, tales como el perdón y el olvido de sus actos. (p. 24)

Así las cosas, se deben compatibilizar dos elementos frente a la comprensión del sistema institucional que se desarrolla a partir de los Acuerdos de Paz con las Farc: por un lado, las garantías institucionales mínimas establecidas en el artículo 2 de la Constitución y en general en la comprensión del constitucionalismo material y, por otro lado, la firme comprensión de que dicho sistema es excepcional y requiere de esfuerzos institucionales que sean propositivos y se orienten hacia un régimen político inclusivo con los disidentes y reparador con las víctimas. El resultado de esto puede ser una verdadera mutación constitucional que permita un reacomodamiento de las garantías sin que estas se afecten, pero que posibiliten un relato constitucional con mayor legitimidad.

\section{Sistemas de control en la Constitución frente a los procedimientos abreviados de reforma y legislación (fast track)}

El cuestionamiento que queda por plantear es hasta qué punto las reformas y medidas elaboradas en el marco de la justicia transicional y todos los componentes que la integran se ajustan al sistema constitucional actual. ¿Puede este constitucionalismo resolver las tensiones evidentes que surgen por la aplicación de este tipo de justicia? De manera 
concreta, es posible preguntar si tiene sentido analizar la constitucionalidad de los procedimientos abreviados de reforma y legislación que sirven de instrumento para soportar los pilares del Acuerdo de Paz o si es necesario acudir a otro tipo de criterios.

\section{Los pilares del control frente al procedimiento legislativo especial para la paz}

Como se señaló, el sistema de controles posee varias instituciones clave a la hora de verificar si un esquema abreviado de legislación es violatorio de la Constitución. Estas instituciones corresponden al sistema cruzado de controles que comprende tanto la separación funcional y la autonomía de las ramas del poder público y de los órganos autónomos como el empleo del principio de legalidad en todas sus actuaciones, junto con la defensa de los derechos fundamentales. Esto implica, desde luego, la aplicación del principio de debido proceso sustantivo como eje articular de toda actuación en el marco del Estado constitucional. Al respecto, señala Díaz Revorio (1997):

Actualmente puede afirmarse que el procedural due process garantiza la existencia de un proceso justo (fair decision-making process) a la hora de tomar cualquier acción gubernamental que limite la vida, libertad o propiedad, aunque no afecta al contenido de la propia medida; en cambio, el substantive due process implica la determinación judicial de la compatibilidad del contenido de una ley o acción gubernamental con la Constitución. Según la interpretación del Tribunal Supremo, para que una ley no infrinja los límites del "proceso debido sustantivo" debe ser "razonable" y "no arbitraria". (p. 464)

Así, el debido proceso sustantivo se conecta con el control de constitucionalidad y con el auge de garantías más fuertes frente a la comprensión del sistema constitucional de controles no solo en la perspectiva del principio de separación de poderes y de frenos y contrapesos, sino también desde el sistema de derechos de los ciudadanos en todas sus actuaciones, tanto frente al Estado como frente a otros individuos (Wolfe, 1991, p. 221). Por ello, se estructura claramente como un pilar 
central a la hora de definir la compatibilidad de las normas surgidas de los procedimientos especiales creados para el proceso de paz.

De manera particular, podemos mencionar los derechos fundamentales como pilar y, por tanto, como límite de la revisión constitucional. Si bien los derechos se encuentran en medio de la comprensión del concepto de debido proceso sustantivo, es cierto que se requiere cierta especificidad para su revisión. Estos elementos distintivos de los derechos fueron determinados por la Corte Constitucional colombiana y son compartidos por los ordenamientos alemán y español ${ }^{11}$ :

a) Principio de tutela del "contenido esencial" de los derechos. Con este postulado se pretende que la dignidad humana se proteja como núcleo fundamental de todos los derechos, de acuerdo con una lectura sistemática desde su fundamentación axiológica. Sobre este aspecto, se distinguen dos tipos de protección: la vía de control abstracto, que persigue que el legislador no le hurte por medio de la actividad que le es propia, el hacer las leyes, el núcleo esencial a los derechos, y la vía de control concreto, que se establece a través de mecanismos judiciales especiales y de eficacia reforzada, como la acción de tutela.

b) Principio de aplicación inmediata. Sobre este punto en particular, la Corte Constitucional ha dejado claro que todos los derechos son de aplicación inmediata ${ }^{12}$. Ello se entiende por lo dispuesto en el artículo 1.3 de la Ley Fundamental alemana,

11 Las diferencias entre los tribunales europeos y el nacional se ubican en la intensidad con que esos postulados son aplicados y en los derechos que cubre. En temas de derechos que abarcan acciones positivas del Estado, estos axiomas tienen aplicación restrictiva en los primeros y, algunas veces, en el segundo. También se harán patentes las diferencias en las consecuencias según los derechos, puesto que cada ordenamiento establece las jerarquías de derechos de manera distinta.

12 Ahora bien, no solo los derechos tienen esta cualidad, puesto que la Constitución en general goza de ese carácter como norma (Sentencia C-155 de 1999). 
lo mismo que en el 53.1 de la Constitución española ${ }^{13}$, es decir, la vinculación de los derechos como pautas obligatorias para los poderes públicos y como parte integral del thelos constitucional. Sin embargo, la aplicación inmediata tiene varios aspectos que es necesario tener en cuenta. Por una parte, saber si el principio de aplicación inmediata implica la posibilidad de ejercer la acción de tutela para cierta clase de derechos. Por otra parte, en el caso particular de los derechos prestacionales es necesario saber si, además de la tutela, dicha aplicación inmediata se puede leer como eficacia inmediata, es decir, como un mandato que compromete sin desarrollo legal a que, sin dilaciones, las autoridades correspondientes inicien acciones para la protección y el desarrollo del derecho. En otras palabras, todos los derechos, en aplicación del reconocimiento de la dignidad humana como valor fundante, no responden a expresiones programáticas y gozan del mismo valor que otras normas, en el sentido del artículo 4 de la Constitución Política, es decir, del principio de eficacia normativa directa de la Constitución.

c) Principio de la interpretación más favorable. En observancia del artículo 4, todas las normas del ordenamiento deben ser interpretadas de manera tal que se busque no solo la constitucionalidad de estas, sino que, además, deberá tenerse como objetivo el desarrollo y la efectividad de los derechos. Este tipo de interpretación es la piedra angular que permite dotar al sistema constitucional de auténtico dinamismo. No basta, por tanto, con una observancia material y formal de los derechos como objetos "dados" de antemano por la Constitución,

13 Artículo 1, núm. 3, de la Constitución alemana que dice: "Los derechos fundamentales relacionados a continuación vinculan a los poderes legislativo, ejecutivo y judicial a título de derecho inmediatamente aplicable.”; artículo 53 de la Constitución española: "1. Los derechos y libertades reconocidos en el Capítulo segundo del presente título vinculan a todos los poderes públicos. Solo por ley, que en todo caso deberá respetar su contenido esencial, podrá regularse el ejercicio de tales derechos y libertades, que se tutelarán de acuerdo con lo previsto en el artículo 161.1.a". 
ya que estos se encuentran siempre en movimiento (Borowski, 2003), conforme a las necesidades de los seres humanos y de la sociedad, obligando, de acuerdo con las diferentes circunstancias, a efectuar los ajustes hermenéuticos necesarios. Por otra parte, la Carta fundamental contiene igualmente derechos cuya realización es de carácter progresivo, de manera tal que las normas que tengan ese carácter deberán apuntar a que día a día se consolide su disfrute efectivo.

d) Principio de la eficacia frente a terceros o frente a particulares. Como parte del concepto de persona en la Constitución de 1991, la eficacia de los derechos no se entiende únicamente de forma vertical, es decir, del Estado y sus órganos hacia el ciudadano, sino que el principio de la dignidad humana produce una ruptura con la visión liberal, de acuerdo con la cual los negocios y los asuntos de carácter privado, por hacer parte de la autonomía de la voluntad, no permiten la injerencia del Estado. La Constitución, por el contrario, autoriza la injerencia de este en la vida de los individuos como parte del orden de valores que el poder público está llamado a propiciar. De este presupuesto se desprende la posibilidad inequívoca de exigir, por vía de tutela, el respeto de los derechos fundamentales frente a los excesos en los que puedan incurrir los particulares que efectivamente lesionan dichos derechos ${ }^{14}$.

Así las cosas, las normas del sistema de refrendación de los acuerdos deberán respetar estos fundamentos para que puedan construirse en un puente comunicante entre la legislación normal y las tensiones presentes en los marcos normativos para la paz.

14 La Drittwirkung del derecho alemán no tuvo mayores problemas para su aplicación en el ordenamiento nacional, ya que las normas que regularon el asunto, especialmente el decreto que reglamentó la tutela, dejó abierta de forma expresa la posibilidad de su aplicación a los actos lesivos de los particulares con respecto a los derechos fundamentales de otra persona (Estrada, 2000). 


\section{El Acto Legislativo n. ${ }^{\circ} 1$ de 2016 y el procedimiento especial legislativo}

Al cotejar el contenido del acto legislativo podemos destacar las siguientes características:

a) Iniciativa privativa del Gobierno. Este asunto, tratado en la regla A del artículo 1, no es nuevo en el ordenamiento jurídico colombiano. Tanto la Constitución como la Ley 5 de 1992 establecen diferentes materias que son de iniciativa legislativa privativa del Gobierno. Como criterio general, podemos advertir que tienen relación directa con sus funciones constitucionales. Leyes como las de ratificación de tratados internacionales y las del presupuesto son un claro ejemplo de esto. La seguridad pública y la negociación con los grupos armados al margen de la ley son una competencia del Gobierno, de suerte que la implementación de los acuerdos debe respetar este ámbito competencial.

b) Trámite abreviado y preferencial. El objeto de los procedimientos que se surten de acuerdo con la Ley 5 de 1992 no es otro que el desarrollo del principio de autonomía de las ramas del poder público y el de la concreción del principio democrático. Por ello, cabe preguntarse si acortar dichos plazos viola estos principios. La Corte Constitucional ha insistido en el tema, señalando que estas formas de aprobación legal no son accesorias y comportan, por tanto, la materialización de esos principios. Ahora bien, ¿es posible cambiarlas, como en efecto lo hace el acto legislativo en cuestión? Consideramos que acortar los tiempos de debate y plantear el procedimiento de sesiones conjuntas entre el Senado y la Cámara de Representantes reviste una clara limitación al principio democrático y al debido proceso sustantivo establecido en la formación de leyes. Pero la limitación en esta materia no es arbitraria ni proviene de la ruptura de un marco referencial general de control. Cabe advertir que las limitaciones a los principios son recurrentes en los sistemas constitucionales actuales y que no existe por ello 
en todos los casos, prima facie, la idea de que la limitación no pueda adaptarse al caso concreto. Lo que claramente no puede ocurrir es el desmantelamiento del principio o derecho, lo cual implicaría la afectación directa de su núcleo esencial. En el caso en examen, dichos procedimientos, si bien fueron reducidos y priorizados, se enfrentan en este contexto a las consecuencias de la aplicación de otros principios, como los derechos de los colombianos afectados por el conflicto armado y de los mismos combatientes, legales e ilegales, que reciben las afectaciones de la guerra de forma directa.

Así las cosas, es razonable pensar que, en este caso, el procedimiento no viola en sí mismo los derechos de las víctimas, como tampoco el principio democrático ni la separación de poderes, toda vez que no se sustituyó la competencia del legislador por otra rama u órgano, sino que recibe una restricción frente a temas específicos. Un argumento que fortalece la tesis según la cual estamos ante una restricción y no ante la suspensión o vaciamiento de los derechos o de la separación de poderes es el hecho de que el Congreso actúa en sesiones conjuntas y bajo las mayorías impuestas por la misma Constitución, asunto que se convierte en una clara salvaguarda frente a la afectación que se presenta, así como la existencia del control automático por parte de la Corte Constitucional de las normas así aprobadas. En el caso de los actos legislativos, por ejemplo, se mantiene la regla de la mayoría absoluta que existe para la segunda ronda de discusiones en los procedimientos ordinarios de reforma. Cabe señalar que rara vez un acto legislativo ordinario no supera la primera ronda que se logra con mayoría simple, y es en realidad la segunda vuelta de discusiones la que genera dificultades, justamente por el requisito de la mayoría absoluta. Esto significa que, aunque se insiste en que estamos frente a una restricción, se mantiene el procedimiento gravoso que genera la garantía de discusión y ve en esta el requisito de mayoría como una forma clara de protección de la misma Constitución y su estructura de separación de poderes. 
c) El aval del gobierno en los contenidos a discutir. Claramente, este es uno de los temas más polémicos del acto legislativo en cuestión, dado que restringe de manera clara la capacidad del legislador de participar y aportar elementos que son fruto del concenso propio del Congreso. Esta situación convierte la discusión parlamentaria en un escenario de refrendación permanente de lo que el Gobierno haya señalado. Por ello, la Corte, en su Sentencia C-332 de 2017 (M. P. Antonio José Lizarazo), señaló:

Nótese cómo, conforme a la regulación planteada, la actividad de decisión e incidencia en las iniciativas adoptadas bajo el procedimiento legislativo especial, termina siendo un asunto subordinado a la voluntad del Gobierno, a partir del mecanismo de los avales. En consecuencia, se sustituye el eje axial de la separación y equilibrio entre los poderes públicos, configurándose por parte del legislador un exceso en su poder de reforma constitucional. Esto debido a que se excluye al Congreso de la posibilidad de ejercer su margen de apreciación respecto del proyecto que somete el Gobierno a su consideración. Igualmente, la restricción a la capacidad deliberativa y decisoria del Congreso incide, también, en la capacidad para la construcción de consensos políticos y democráticos, necesarios para la legitimidad del proceso de implementación.

Aunque la Constitución reconoce al Gobierno, en algunos casos, la posibilidad de determinar de antemano los contenidos a discutir en el legislativo ${ }^{15}$, la Corte considera que en aras de la paz no es posible afectar la estructura constitucional de separación de poderes, que sirve a la vez como fundamento de la misma. Sería una grave equivocación institucional asumir que los argumentos en favor de la paz se conviertan al mismo tiempo en aquellos que dañan las bases sobre las cuales se plantea

15 Esto lo hace a través del reconocimiento al Gobierno de la iniciativa exclusiva para proponer proyectos de ley en ciertas materias, según los dispuesto en el artículo 154. 
la reinstitucionalización del país. Una de las virtudes del constitucionalismo es precisamente comprender que no existe ningún derecho o principio superior per se, dado que esto configuraría una especie de la tiranía de ese derecho o principio y que debe someterse, por tanto, a una mirada global para garantizar la coherencia del mismo. Por ello, es necesario que el Congreso tenga la posibilidad de discutir los temas, eso sí, bajo el marco general del Acuerdo de Paz, pues no puede olvidarse que estamos en un escenario transicional, y aunque debemos salvaguardar los principios básicos del control, no podemos ver todo el análisis normativo como si estuviésemos en condiciones de normalidad constitucional. Es una excepcionalidad reglada y garantista, pero, al fin y al cabo, una excepcionalidad.

d) El acuerdo como límite al legislador. En este sentido, la Corte ha señalado que el numeral h del artículo 1 del acto legislativo en cuestión viola el principio de separación de poderes, dado que si bien el Gobierno tiene la competencia de suscribir acuerdos de paz, este acuerdo es de contenido político, y por ello no obliga directamente al Congreso en su implementación. Sin embargo, el legislador debe respetar el principio de conexidad normativa que implica que no puede romperse la coherencia del acto o de la ley.

Por otro lado, también debe resaltarse, como previamente se expuso, que algunos de los contenidos del Acuerdo son más específicos que otros. Por ello, en la medida en que debe cumplirse el requisito de conexidad, la amplitud de la potestad normativa del Congreso dependerá de esa especificidad. Así, puede válidamente plantearse que algunos contenidos del Acuerdo tienen un grado de especificidad tal que limitan en buena medida el margen de apreciación del legislador. En cambio, otros contenidos más amplios pueden ser desarrollados de diferentes maneras, de modo que en ese caso el margen de apreciación legislativa es mucho más amplio, teniendo como límite la conexidad entre la medida adoptada y la implementación efectiva del Acuerdo (Sentencia C-332 de 2017). 
Al respecto también señala la Corte que en caso de considerar que se realizan reformas al Acuerdo que lo afectan gravemente, el Gobierno puede hacer uso de su poder de objeción para remediar estas afectaciones. Agrega este tribunal que el legislador también debe comportarse con transparencia y no utilizar el procedimiento como mecanismo dilatorio y desleal para evitar el avance del trámite legislativo.

No obstante, esta postura de la Corte plantea varios interrogantes, dado que la esencia y la finalidad del ejercicio de un acuerdo de esta naturaleza no pueden ser afectadas de forma estructural por el legislador, pues convierte esa competencia en un mero trámite y le quita su importancia. Desconoce la Corte el contexto del acuerdo, pues no solo implica un esfuerzo institucional enorme, sino que además representa de forma directa la vida de quienes lo suscribieron, pues los exguerrilleros esperan del Estado el cumplimiento de estos compromisos y no un limbo jurídico y político que socava esos mismos esfuerzos. Cuando el presidente negocia los acuerdos lo hace como jefe de Estado y no solo como jefe de Gobierno, y, por ello, compromete al Estado completo. Esto no significa, como vimos atrás, que el Gobierno no cuente con controles de diversa naturaleza durante el proceso de discusión y de aprobación. Pero aceptar, de forma tan amplia como lo hace la Corte, la posibilidad de reformar los acuerdos puede generar consecuencias indeseables y de enorme gravedad para los derechos de los colombianos, que afectan no solo a las víctimas sino también a los exguerrilleros que, desde luego, también son colombianos. Cuando el Tribunal recuerda la posibilidad de objetar las normas contrarias al Acuerdo se evidencia la falta de análisis del contexto y sus consecuencias, pues la idea misma de proponer un procedimiento abreviado se fundamenta en los efectos nocivos de largos periodos sin las definiciones centrales del acuerdo, que comprometen nada más y nada menos que la estabilidad jurídica de los excombatientes, así como los procedimientos que garantizan la 
justicia y la reparación de las víctimas. Es el de la Corte, en conclusión, un análisis exclusivamente normativo que riñe con el constitucionalismo contemporáneo, preocupado este, de forma central, por los impactos de las decisiones judiciales y, desde luego, por la eficacia de los derechos y de las competencias esgrimidas en una constitución.

La referencia de la Corte al principio de conexidad que debe guardar el legislador no parece suficiente como medida de remedio ante el peligro de desarticular o incluso romper los acuerdos (como lo han manifestado ciertos sectores de la oposición), o ante las prácticas de dilación a las cuales hace referencia la misma Corte, las cuales tampoco tendría medios reales de ser limitadas.

\section{Conclusiones}

De acuerdo con la premisa fundamental descrita en la primera parte del trabajo, la cual describe de manera completa que el constitucionalismo es sin duda una práctica institucional desarrollada para el control del poder, está claro que las constituciones modernas se enfocaron, por tanto, en la tecnificación de ese control. Es decir que las tradiciones inglesa, norteamericana y francesa establecieron diversos mecanismos que sirven, en efecto, para desarrollar sistemas de control frente al peligro de la univocidad de un poder político concentrado, que a todas luces resulta siempre una amenaza a la sociedad misma, y, en especial, al concepto de derechos naturales esgrimido en la literatura que cimienta las instituciones contemporáneas del derecho constitucional.

Es, por tanto, cierta la hipótesis de que el constitucionalismo y su herramienta más poderosa, la constitución, es el eje sobre el cual se construyen las garantías institucionales, reconocidas como elementos que requieren permanencia y solidez, pues sirven no solo en tiempos de estabilidad política, sino especialmente cuando los cimientos de la sociedad se ven amenazados por las coyunturas políticas, sociales o económicas que hacen dudar de lo acordado. 
En esta línea de pensamiento, la Constitución de 1991 construyó un modelo de constitucionalismo que permitiera resolver las amenazas de la concentración del poder, en especial las generadas por el presidencialismo sin muchas limitaciones. Así, el constituyente dio dos pasos clave para comprender el sistema de control del poder: por un lado, se adscribió al modelo de la soberanía popular, que no divide el poder en partes y que, por el contrario, enfatiza en el pueblo el poder esencial del Estado. En segundo lugar, y como consecuencia de lo anterior, creó un modelo que supera la tridivisión del poder para comprender un modelo organizativo complejo del Estado, en donde las ramas tradicionales orgánicas se conjugan con organismos nuevos y otros ya existentes, pero que ahora gozan de una clara autonomía y un lugar de privilegio en el modelo constitucional. Esto, desde luego, se complementa con un profundo esquema de frenos y contrapesos, en donde interactúan las ramas del poder para conformar el entramado armónico propuesto en el artículo 113 de la Constitución.

Estas premisas son justamente el cimiento para afrontar los retos de un proceso fundamental, pero complejo, como la justicia transicional. El reto general está planteado, de forma que se deben resolver diversos problemas complejos con las herramientas del modelo constitucional para asuntos muy complejos y para los cuales no necesariamente están preparadas estas instituciones. Un elemento crucial de este proceso es la comprensión del marco de regulación y limitación de las competencias entre las diversas ramas del poder público. En especial, resulta central establecer el ámbito competencial del ejecutivo como actor central de la consecución de la paz y de la construcción de una política pública integral en torno a este objetivo.

Uno de esos capítulos esenciales de la delimitación se presenta frente a las competencias del legislador y la capacidad de refrendar, regular y modificar los acuerdos y las reglamentaciones sobre ellos. De ahí que el análisis del fast track resulte un punto clave para comprender no solo el funcionamiento actual de la Constitución, sino también la capacidad institucional para resolver dichas tensiones. En este sentido, se concluye que la Corte ha actuado de acuerdo con los principios clásicos de respeto competencial, autorrestricción y prevalencia de la democracia, pues ha establecido que el ejecutivo no 
puede, aun por un objetivo tan importante como la paz, soslayar la competencia de legislar y que, por ello, corresponde al Congreso debatir y estructurar la reglamentación de las acuerdos, desde luego, conforme a los principios generales del debate parlamentario establecidos en la Constitución y en la Ley 5 de 1992. Sin embargo, esta apuesta de la Corte no desarrolla con suficiente firmeza los límites del legislador. Es decir, se comprende que este no puede modificar en lo sustancial los acuerdos, pues implicaría hacer nugatoria la facultad del Gobierno para realizar este tipo de negociaciones. Esto representa un vacío peligroso que podría afectar gravemente la estructura de lo acordado.

Por último, se considera que la Corte también fue poco enfática en advertir que no se puede instrumentalizar el procedimiento parlamentario para generar demoras innecesarias y entorpecer por esta vía la reglamentación de los acuerdos. Se hace necesario, entonces, establecer un mejor marco competencial que articule esta tensión, de forma que respete el principio de frenos y contrapesos, pero que proteja la búsqueda del valor de paz como parte central del proyecto constitucional colombiano.

\section{Referencias}

Aguiló, J. (2004). La constitución del Estado constitucional. Lima: Palestra; Bogotá: Temis.

Akech, M. (2010). Institutional Reform in the New Constitution of Kenya. Recuperado de http://ictj.org/sites/default/files/ICTJ-Kenya-Institutional-Reform-2010-English.pdf

Aron, R. (2004). Las etapas del pensamiento sociológico. Montesquieu, Comte, Marx, Tocqueville, Durkheim, Pareto, Weber. (Trad. de C. García Trevijano). Madrid: Tecnos.

Beaud, O. (2009). L'histoire du concept de constitution en France. De la constitution politique à la constitution comme statut juridique de l'Etat. Jus Politicum, Autour de la notion de Constitution, 3, 1-29. Recuperado de http:// juspoliticum.com/article/L-histoire-du-concept-de-constitution-en-France-De-la-constitution-politique-a-la-constitution-comme-statut-juridique-de-l-Etat-140.html 
Borowski, M. (2003). La estructura de los derechos fundamentales. Bogotá: Universidad Externado de Colombia.

Canosa Usera, R. (1988). Interpretación constitucional y fórmula política. Madrid: Ilustrada.

Díaz Revorio, J. (1997). Valores superiores e interpretación constitucional. Madrid: CEPC.

Duverger, M. (1976). Los partidos políticos. (Trad. de J. Campos y E. González Pedrero). México: Fondo de Cultura Económica.

Eisenmann, Ch. (1933). L'esprit des Lois et la séparation des pouvoirs. En Mélanges Carré de Malberg (pp. 163-192). París: Librairie du Recueil Sirey.

Estrada, A. (2000). La eficacia de los derechos fundamentales entre particulares. Bogotá: Universidad Externado de Colombia.

Fetscher, I. (2002). La Ilustración en Francia: la Enciclopedia, Montesquieu, Rousseau. En F. Vallespín Oña (comp.), Historia de la teoría política (vol. 3. Ilustración, liberalismo y nacionalismo, pp. 104-174). Madrid: Alianza Editorial.

Friedrich, C. J. (1975). Gobierno constitucional y democracia: teoría y práctica en Europa y América. (Trad. de A. Gil, 2 vols.). Madrid: Instituto de Estudios Políticos.

García Pelayo, M. (2005). Derecho constitucional comparado. Bogotá: Alianza.

Grimm, D. (2006). Constitucionalismo y derechos fundamentales. (Trad. de R. Sanz y J. L. Muñoz). Madrid: Trotta.

Gutiérrez, L. M. (2014). La obligación internacional de investigar, juzgar y sancionar graves violaciones a los derechos humanos en contextos de justicia. Estudios Socio-Jurídicos, (16)2, 23-60. doi: http://dx.doi. org/10.12804/esj16.02.2014.01

Haberle, P. (2002). Pluralismo y constitución: estudios de teoría constitucional de la sociedad abierta. Madrid: Tecnos.

Hamilton, A., Madison, J. y Jay, J. (2001). El federalista. (Trad. de G. Velasco). México: Fondo de Cultura Económica.

Hauriou, A., Gicquel, J. y Gélard, P. (1980). Derecho constitucional e instituciones politicas. (Trad. de J. Gonzales). Barcelona: Ariel.

Hermet, G. (1996). En las fronteras de la democracia. (Trad. de E. Lombera). México: Fondo de Cultura Económica. 
International Center for Transitional Justice (2010). What is Transitional Justice? Recuperado de http://ictj.org/about/transitional-justice

Larrère, C. (2003). Montesquieu. En Ph. Raynaud y S. Rials (dirs.), Dictionnaire de philosophie politique (pp. 467-474). París: Presses Universitaires de France.

Löewenstein, K. (1983). Teoría de la constitución. (Trad. de A. Gallego). Barcelona: Ariel.

Matteucci, N. (2005). Constitucionalismo. En N. Bobbio, N. Matteucci y G. Pasquino (dirs.), Diccionario de política (pp. 335-349). México: Siglo XxI.

McIlwain, C. H. (1991). Constitucionalismo antiguo y moderno. (Trad. de J. Solazábal). Madrid: Centro de Estudios Constitucionales.

Montesquieu, Ch. L. de S. (1984). Del espíritu de las leyes. (Trad. M. Blázquez y P. de Vega, 2 vols.). Barcelona: Ediciones Orbis.

Nevins, A. y Commager, H. S. (1963). Breve historia de los Estados Unidos. Biografía de un pueblo libre. (Trad. de F. M. Torner). México: Compañía General de Ediciones.

Nino, C. S. (1992). Fundamentos de derecho constitucional: análisis filosófico, jurídico y politológico de la práctica constitucional, Buenos Aires: Editorial Astrea.

Organización de las Naciones Unidas (2005). Resolución 2005/70. Derechos humanos y justicia de transición. Recuperado de http://ap.ohchr.org/documents/S/CHR/resolutions/E-CN_4-RES-2005-70.doc

Pérez Royo, J. (1988). Tribunal Constitucional y división de poderes. Madrid: Tecnos.

Pritchett, C. H. (1965). La Constitución americana. Buenos Aires: Tipografía Editora de Argentina.

Richter, M. (1990). Introduction. En Montesquieu, Ch. L. de S., Selected political writings (pp. 1-53). Indianapolis: Hackett Pub.

Sánchez-Cuenca, I. y Lledó, P. (eds.). (2002). Artículos federalistas y antifederalistas: el debate sobre la Constitución americana. Madrid: Alianza Editorial.

Sieyès, E. (1993). Preliminar de la constitución. Reconocimiento y exposición razonada de los derechos del hombre y del ciudadano (1789). En D. Pantoja (ed.), Escritos políticos de Sieyès (pp. 177-189). México: Fondo de Cultura Económica. 
Teitel, R. G. (2003). Transitional Justice Genealogy. Harvard Human Rights Journal, 16, 69-94.

Tomás y Valiente, F. (1996). Constitución. En E. Díaz y A. Ruíz Miguel (eds.), Filosofía política II. Teoría del Estado (pp. 45-61). Madrid: Trotta.

Torres Ávila, J. (2012). El mandato del Estado social de derecho en la constitución colombiana: los derechos sociales y el mínimo vital. Bogotá: USTA.

Uprimny Yepes, R. y Saffon, M. P. (2005). Estándares internacionales y procesos de paz en Colombia. Entre el perdón y el paredón. Preguntas y dilemas de la justicia transicional. Bogotá: Uniandes, Corcas Editores.

Wolfe, C. (1991). Las transformaciones del Derecho Constitucional. Madrid: Civitas. 